\title{
Electrochemical and Corrosion Behavior of 2205 Duplex Stainless Steel in Simulated Concrete Pore Solution
}

\author{
Baosong $\mathrm{Li}^{1, *}$, Weiwei Zhang ${ }^{2}$ \\ College of Mechanics and Materials, Hohai University, Nanjing 211100, China \\ ${ }^{2}$ College of Mechanical and Electrical Engineering, Hohai University, Changzhou 213022, China \\ *E-mail: bsli@hhu.edu.cn
}

doi: $10.20964 / 2017.09 .43$

Received: 14 May 2017 / Accepted: 6 July 2017 / Published: 13 August 2017

\begin{abstract}
In this paper, electrochemical and passivation behavior of 2205 duplex stainless steel (DSS) in simulated concrete pore solution (SCPS) under anoxic condition was studied. The electrochemical impedance spectroscopy (EIS) was mainly employed to evaluate the corrosion behavior of the passive film. The electrochemical behavior of DSS 2205 was investigated by potentiodynamic polarization, EIS, Mott-Schottky methods. The results show that the protective behavior of the passive film of DSS 2205 in SCPS at pH 12.5 is better than that of 13.3 and 13.8. The time for polarization current to reach an steady state will be prolonged with the $\mathrm{pH}$ value increase from 12.5 and be shorten as the formation potential increases. The passive film could display the behavior of both n-type and p-type semiconducting which is related to the formation potential. The optimal polarization potential for passivation of DSS 2205 in SCPS is related to the $E_{\text {corr }}$ of the passive film, which is in the range of $400 \mathrm{mV}$ to $0 \mathrm{mV}$.
\end{abstract}

Keywords: passivation; electrochemical impedance spectroscopy; 2205 duplex stainless steel; electrochemical behavior; simulated concrete pore solution

\section{$\underline{\text { FULL TEXT }}$}

(C) 2017 The Authors. Published by ESG (www.electrochemsci.org). This article is an open access article distributed under the terms and conditions of the Creative Commons Attribution license (http://creativecommons.org/licenses/by/4.0/). 